DAGNINO, Evelina (org.). 2002. Sociedade civil e espaços públicos no Brasil. São Paulo : Paz e Terra.

\title{
A DIVERSIDADE DE ESPAÇOS PÚBLICOS NUM CENÁRIO DEMOCRÁTICO
}

\author{
Denise Ratmann Arruda Colin \\ Universidade Federal do Paraná
}

Sociedade civil e espaços públicos no Brasil é resultado de uma pesquisa realizada no período de 1999 e 2000, como parte de um projeto internacional de investigação. Seis estudos de caso são apresentados. O objetivo principal foi avaliar a desenvoltura dos diferentes espaços públicos instituídos recentemente no Brasil. A pesquisa abraçou desde os espaços mais formalizados com funções consultivas ou deliberativas, até os mais informais, destinados à execução de políticas públicas, ou os que têm como objetivo principal a pressão dos movimentos sociais em relação à atuação do Estado, bem como o monitoramento de sua atuação, dentro da lógica do processo de construção democrática.

No seu conjunto a coletânea não se propôs a estabelecer interações ou comparações com as pesquisas desenvolvidas nos outros países, mas um artigo dedicou-se a abordar a temática da relação da sociedade civil com a governabilidade democrática no panorama latino-americano, em especial no México, nos Andes (Peru e Colômbia) e no Cone Sul (Argentina e Chile). Da mesma forma, a obra não definiu uma correlação entre as experiências investigadas no Brasil, visto que elas foram elencadas separadamente, considerando o seu respectivo contexto. Ao discorrer sobre tais experiências tentaremos, ainda que timidamente, superar tal fragmentação.

Na primeira parte do texto apresentaremos uma breve descrição de cada um dos estudos de caso, concentrando o foco nos avanços e retrocessos por nós percebidos. Nesse momento será interessante estabelecermos vínculos com as conclusões aventadas por Dagnino, a coordenadora da pesquisa, a respeito das possibilidades de exercício democrático encontradas nesses espaços públicos, em especial no que tange à participação da sociedade civil e de sua relação com o Estado. A seguir, restarão assinaladas algumas evidências e similaridades entre as experiências dos demais países latino-americanos e o Brasil.

A obra partiu do pressuposto de que o processo de construção democrática não é linear e homogêneo, mas crivado por aspectos complexos, contraditórios e oscilantes, nos quais tanto o Estado como a sociedade reproduzem concepções e interesses plurais e, por vezes, antagônicos.

O primeiro estudo ("O orçamento participativo: as experiências de Porto Alegre e de Belo Horizonte") procedeu a uma análise comparada das práticas do orçamento participativo nos municípios de Porto Alegre e de Belo Horizonte, apontando como novidade o reconhecimento desse instrumento como crucial para o bom desempenho da gestão social dentro do espectro de disputa entre as variadas propostas e discursos políticos. Restou comprovado que as assembléias regionais de eleição das prioridades introduzem uma forma democrática e pública de negociação entre o poder público e a população, substituindo a tradição particularista e clientelista de distribuição de recursos e favores.

$\mathrm{O}$ autor vincula o sucesso do orçamento participativo à pré-existência de práticas associativas estabelecidas nos dois municípios e no estabelecimento de uma sistemática de monitoramento das decisões (ainda que de maneiras distintas), na medida em que sedimenta o conceito de participação. Ele enfatiza também a capacidade do orçamento participativo em "transferir dos mediadores políticos para a população a decisão sobre distribuição de bens materiais através da criação de um conjunto de elementos públicos: assembléias, listas de acesso anterior a bens materiais, critérios de carência" (AVRITZER, 2002, p. 39).

Entendemos cabível registrar que tal anotação acaba referendando o estudo de desempenho institucional dos governos regionais na Itália realizado por Putnam, ao constatar a convergência de maior desempenho ao serem sinalizadas a vigência de um engajamento cívico, com os cidadãos imbuídos de espírito público, por 
relações políticas igualitárias e por uma estrutura social firmada em relações horizontais de reciprocidade e de cooperação (PUTNAM, 1996).

A conclusão semelhante chegou Teixeira ao registrar, no capítulo 4 ("A atuação das organizações nãogovernamentais: entre o Estado e o conjunto da sociedade"), que "quanto maior a horizontalidade nas relações entre governos e ONGs, quanto maior proximidade entre as organizações e seu público atingido, mais chegamos próximos de valores democráticos, que são apreendidos nos processos de confronto e construção de consensos, tanto pelos agentes governamentais quanto pela sociedade mais ampla" (TEIXEIRA, 2002, p. 140).

A mesma linha de raciocínio seguiu o sexto estudo de caso, ao demonstrar que "as variações do desenho institucional, as visões de participação e representação e as forças políticas que apoiam ou ocupam tais espaços influem no seu potencial para ampliar e democratizar a gestão estadual e fomentar a igualdade entre homens e mulheres, ou para conformar, de modo domesticado, a participação das mulheres e sua influência na definição de políticas que venham a construir uma justiça de gênero" (ESMERALDO \& SAID, 2002, p. 231).

Por outro lado, o orçamento participativo apresenta três limites: 1) a rarefeita democratização entre os próprios atores sociais; 2) a impossibilidade de estendê-lo para áreas alternativas de políticas públicas, definindo critérios de acessibilidade e de qualidade, e 3) a ênfase na distribuição de recursos, esvaziando as discussões do conteúdo e execução dos programas.

Salientamos que outras críticas são dirigidas a essa dinâmica de participação, tais como a restrição da deliberação a uma parcela reduzida do orçamento, vinculada aos investimentos; a potencialidade em gerar conflitos de competência com os órgãos do poder Executivo e, até mesmo, com o poder Legislativo (BORBA, 2000; DIAS, 2000).

O capítulo seguinte ("Os conselhos gestores e a democratização das políticas públicas no Brasil”) dedicouse a apreciar o funcionamento dos conselhos gestores de políticas públicas, privilegiando os da área de assistência social, da criança e adolescente e de saúde, e ponderou que o discurso neoliberal de participação busca a democratização do processo dentro das regras de eficácia dos resultados.

Diante do alerta da autora, entendemos conveniente demarcar os distintos enfoques de participação: o viés neoliberal, de descomprometimento do Estado e de repasse dos serviços para a sociedade, e o viés democrático, de cunho pedagógico e inclusivo, como pré-condição para a cidadania.

No capítulo 7 ("O Conselho Cearense de Direitos da Mulher - espaço de interlocução entre as demandas dos movimentos de mulheres e o Estado") as autoras também chamam a atenção para a falácia que é a proposta de instituição de um Estado mínimo, mediante, inclusive, a terceirização das políticas públicas, como resposta positiva à inoperância e lentidão do Estado, negando a primazia de sua responsabilidade frente às políticas setoriais, quando afirmam que o debate público dos conflitos e a partilha de poder têm sido negados em nome do discurso de redução e desburocratização do Estado e de desmonte das políticas públicas, que elimina os canais de interlocução com os diversos setores da sociedade.

Reconhecendo que "os conselhos gestores de políticas públicas indicam uma importante vitória na luta pela democratização do processo de decisão" (TATAGIBA, 2002, p. 54-55), interessou para a investigação identificar até que ponto tem sido viável reverter, na dinâmica concreta de funcionamento dos conselhos, a centralidade e a liderança do Estado na definição das políticas e das prioridades sociais, questão recorrente no estudo da Ciência Política.

Nessa vertente, o capítulo sobre "Os gestores e a democratização das políticas públicas no Brasil” destacou as possibilidades e os limites encontrados pelo conselho para promover essa superação:

a) limites: dificuldade dos conselheiros em admitir a pluralidade de interesses e a existência e legitimidade do conflito; imposição unilateral dos interesses temáticos do Estado; recusa do Estado em partilhar o poder de decisão, traduzido nas reiteradas tentativas de neutralização e enfraquecimento do conselho; utilização das estratégias de boicote, de esvaziamento, de cooptação e de manipulação pelo Estado, no caso de impossibilidade de constituição de um Conselho de "aliados"; carência de recursos e de infra-estrutura para o adequado funcionamento do conselho; domínio dos recursos públicos pelo Estado, gerando dependência e controle dos conselhos e das entidades não-governamentais; tênue relação estabelecida entre o conselheiro e a entidade que representa; despreparo dos conselheiros para exercer as suas funções; centralidade do Estado na elaboração da pauta; manutenção de padrões clientelistas na relação entre o Estado e a sociedade; precariedade de recursos financeiros destinados ao fundo ou ausência de depósitos; não publicização dos recursos públicos, 
reforçada pela cultura política marcada pela apropriação privada dos bens públicos; fragilidade deliberativa do conselho em função de sua ambígüa inserção no conjunto da institucionalidade;

b) possibilidades: heterogeneidade na composição; respeito à diferença, ao confronto argumentativo e à tentativa de diálogo entre grupos que defendem interesses distintos; capacidade de construir adesões em torno de projetos específicos ou temas pontuais; assentamento da pactuação e da troca de idéias como procedimentos para a tomada de decisão; explicitação dos conflitos dentro do governo e a compreensão do Estado como ator não monolítico; luta permanente para o repasse regular dos recursos públicos para o fundo; publicização dos espaços de discussão, negociação e deliberação; função pedagógica da participação na construção da cidadania e na reinvenção dos padrões de convivência democrática entre novos sujeitos políticos; estabelecimento de consensos para além da esfera do Conselho; acesso às informações; conhecimento do funcionamento da máquina administrativa.

Dagnino aponta que nos estudos de casos efetuados o foco da natureza dos conflitos recai na dificuldade em partilhar o poder de decisão, na medida em que, mesmo quando essa partilha acontece, mostra-se restrita e limitada, sem ampliar o espectro de deliberação das políticas públicas para impactos mais significativos na sociedade.

Em contrapartida, é preciso ressaltar a grande novidade: todas as experiências enalteceram o reconhecimento da pluralidade de interesses, da importância da possibilidade de expressão do confronto e da contraposição, bem como o estabelecimento de pactuações e de consensos como condição sine qua non para a consolidação da democracia. Lembramos que autores como Dahl e Mouffe defendem arduamente as mesmas posições (DAHL, 1997; MOUFFE, 2001).

Tatagiba conclui que os conselhos gestores no Brasil "parecem regidos por uma lógica contra-ditória, marcada pela correlação entre o peso relativo dos traços autoritários das instituições estatais brasileiras e o peso relativo do recente adensamento da sociedade, através da criação de novos espaços de negociação e representação políticas. Os conselhos, nesse sentido, encarnam as ambigüidades, os desafios e as promessas de uma forma partilhada de construção de políticas públicas, sob a égide de uma cultura política na qual predominam referências autoritárias [...] direcionando-os para uma baixa capacidade propositiva e um reduzido poder de influência sobre o processo de definição das políticas públicas" (TATAGIBA, 2002, p. 90, 98).

Mesmo assim, o seu grau de importância e contribuição positiva tanto podem estar vinculados à sua capacidade de introduzir a participação popular na ação deliberativa, como podem estar relacionados ao controle social do Estado, dos recursos públicos e dos projetos desenvolvidos ou, ainda, à eficiente vocalização das demandas.

É oportuno acrescentar o registro da característica já levantada por Teixeira de conceber os conselhos como estruturas híbridas, compostas por membros do Estado e da sociedade, na constituição da esfera pública, criando uma nova institucionalidade no país, capaz de quebrar o monopólio de atores tradicionais como: $\mathrm{o}$ partido, os Poderes Executivo e Legislativo, o sindicato, os grupos de pressão etc. (TEIXEIRA, 2000). Lembramos, ainda, que esse foi também um dos aspectos assinalados como responsáveis pelo êxito do orçamento participativo.

O capítulo 4 destina-se a investigar as múltiplas formas de relacionamento das organizações nãogovernamentais com o Estado e a (re)definição dos seus vínculos com o conjunto da sociedade, marcados por três situações concomitantes: 1) a abertura democrática, que instituiu espaços de interlocução entre Estado e sociedade; 2) a construção de redes e articulações, no âmbito internacional, em torno de diversos temas, e 3 ) a introdução dos princípios neoliberais de ajustes estruturais e fiscais, transferindo para a sociedade a responsabilidade de colaboração em políticas compensatórias.

Dentro desse espectro foram encontradas três formas de relação das organizações não-governamentais (ONGs) com o Estado, determinadas pelo projeto político que perpassa a relação, pelo poder efetivo de cada uma das partes envolvidas e pelo grau de empenho de cada qual: 1) menos formais, ora ligadas aos movimentos de pressão, monitoramento e crítica ao Estado, ora voltadas a proposição, colaboração e acompanhamento das ações desencadeadas pelos órgãos estatais; 2) formais, nas quais o Estado contrata a prestação dos serviços das ONGs, gerando competição semelhante à lógica mercantil; 3) mais participativa, na qual se consolida a elaboração, execução e avaliação conjunta de um serviço a ser prestado pelo poder público, ou pela ONG, ou por ambos, ao comparecer a partilha de poder. 
Houve unanimidade de todos os entrevistados ao identificarem as principais dificuldades encontradas nessa relação: preponderância da burocracia estatal; diferença de prioridades entre o governo e as entidades; despreparo e falta de sensibilidade do Estado como também das ONGs para determinadas questões; alta rotatividade de programas de governo dentro do Estado, ao passo que também houve o reconhecimento de brechas dentro do próprio governo, no qual muitos funcionários comungam dos interesses das organizações, estabelecendo uma teia de comunicação interpessoal e interorganizacional.

Esse fator foi também referendado quando se procedeu à observação dos projetos de educação dos jovens e adultos do MST, no capítulo 6 ("As relações entre o Movimento dos Sem-Terra e o Estado: programas de alfabetização de jovens e adultos no Paraná"), anteriormente anotado por outros autores (ALVAREZ \& DAGNINO, 1995). Ressaltamos que essas brechas são fruto da complexidade e do caráter contraditório do Estado, que nega seu aspecto de bloco hermético e monolítico, capaz de sempre fazer preponderar suas intenções.

Outro estudo de caso versou sobre as nuances sofridas pelo Fórum Nacional de Reforma Urbana. As fragilidades apresentadas resultaram, em parte, dos momentos de ausência de sintonia entre as agendas de seus integrantes, outras vezes pela precariedade da estrutura operativa e financeira que lhe dá suporte e, em parte, por ter concentrado seus esforços junto ao Congresso Nacional, que tem seu poder centralizado na mesa diretora e no colégio de líderes, espaços pouco acessíveis às interlocuções com a sociedade. Salientamos que a última observação corrobora estudos reconhecidos na Ciência Política brasileira (FIGUEIREDO \& LIMONGI, 1994). Ocorreu também a dificuldade de estabelecer uma interlocução com o governo a respeito da validação dos acordos internacionais e a demora na aprovação do Estatuto da Cidade.

O eixo comum com as outras experiências está circunscrito à manifestação das diferenças e ao reconhecimento de que a convergência das reivindicações coletivas, mediante a articulação de sujeitos diferenciados, produzem a oportunidade de negociações e de consensos, além de aumentar a possibilidade de compor a agenda pública. A similaridade das conclusões entre as experiências revela, então, que as práticas e o processo de democratização no Brasil são lentos e com oscilações, concomitantes entre atitudes de negociação e de repressão, caracterizando um movimento de construção e reconstrução permanente, no qual o espaço das relações entre o Estado e a sociedade é definido a partir de correlação de forças e de uma disputa pelo controle das relações que nele se manifestam.

O estudo subseqüente ("As relações entre o Movimento dos Sem-Terra e o Estado: programas de alfabetização de jovens e adultos no Paraná") trata das relações estabelecidas entre o Movimento dos Sem Terra (MST) e o estado do Paraná, por meio da Secretaria de Educação, relativamente à demanda para a promoção da educação de jovens e adultos, frente ao elevado número de analfabetos no estado do Paraná. Essas relações apresentaram formatos diferenciados, seguindo o fluxo dos momentos históricos e políticos, tais como: a) os momentos de oposição e conflitos acirrados, diante das ocupações/desocupações de terra ou de órgãos públicos, quando o governo suspendia o trabalho em conjunto; b) os momentos de negociações e consensos, em que foram estabelecidos os convênios de parceria, e c) os momentos de ofensivas nos meios de comunicação em geral, em que ambos os lados posicionavam-se em confronto, quando o governo alegava falta de verbas e o Movimento indicava o posicionamento político-ideológico neoliberal do novo grupo que ocupou o governo como a justificativa para obstaculizar os projetos.

Nesse contexto, a viabilidade da parceria esteve ligada à participação das universidades estaduais na coordenação do projeto; à afinidade dos professores e acadêmicos com a proposta pedagógica do MST; à defesa dos projetos de educação popular por parte de alguns funcionários da Secretaria de Estado da Educação; à existência e ao envolvimento dos professores leigos pertencentes ao movimento e à solicitação de seus membros por educação; ao acúmulo de experiências do MST na área de formação pedagógica e política, como condição necessária para se atingir uma visão crítica, entre outros motivos.

Todavia, ficou nítido que para o MST a luta pela terra adquire um objetivo mais amplo, de transformação da organização da sociedade, capaz inclusive de tornar secundária a defesa do direito à educação. Por sua vez, $\mathrm{o}$ governo, em especial as últimas gestões estaduais, nos períodos de 1995-1998 e de 1999-2002, também deixaram em segundo plano o seu dever constitucional de fornecimento da educação fundamental e passaram a buscar a anulação das ações e da visibilidade do Movimento, face ao fortalecimento e legitimidade do mesmo na sociedade.

No sexto estudo de caso ("O Conselho Cearense de Direitos da Mulher - espaço de interlocução entre as 
demandas dos movimentos de mulheres e o Estado") as autoras evidenciaram criticamente a emboscada em que se encontrava o Conselho Cearense dos Direitos da Mulher, visto que, embora os governantes do período analisado (1997-2002) tivessem adotado modelos diferentes de gestão, mais populista (Ciro Gomes) ou mais descentralizado (Tasso Jereissati), ambos consideravam apenas as entidades que se afinavam com os seus propósitos, portanto os seus pares, como representantes da sociedade civil.

Por seu turno, o Conselho acabou desvirtuando-se de seus principais objetivos, quando se distanciou das lutas mais específicas do movimento feminista para fortalecer bandeiras democráticas mais amplas que sustentavam a militância político-partidária de suas integrantes, e quando se eximiu de um debate teórico com a Academia, como forma de garantir a fundamentação das concepções a serem defendidas.

Ao delinear-se um paralelo com as análises da América Latina, diagnosticou-se que "a natureza da sociedade civil tem a ver com as particularidades do desenvolvimento histórico de nossas sociedades, em que sofremos o impacto combinado de reformas econômicas neoliberais, experiências autoritárias e processos inacabados de democratização política" (PANFICHI \& CHIRINOS, 2002, p. 305), mesmo estando submetidos a ritmos e características díspares entre os países dos Andes e do Cone Sul. Pode-se acrescentar, ainda, a sua dependência com o Estado e até com os grupos de poder econômico, e a ausência de uma separação clara entre as esferas pública e privada no exercício da gestão.

O incentivo à participação da sociedade civil nos processos de tomada de decisão e execução de políticas públicas, elemento fundamental na busca de desenvolvimento, eqüidade e democracia, foi sentido de maneira uniforme por todos os países, especialmente após o Consenso de Santiago, etapa posterior ao Consenso de Washington, que enfatizou a necessidade de reformas institucionais em educação, finanças, justiça e administração pública, definindo papéis complementares do Estado e da sociedade.

Em conseqüência, passou-se a enfocar integralmente o desenvolvimento econômico e social da América Latina, após concluir que a ação espontânea do mercado e a existência de um Estado minimalista não alterou as condições de pobreza e desigualdade enfrentadas pela população, tampouco gerou crescimento e desenvolvimento partilhado.

O México foi tomado como um caso exemplar, onde a adoção das medidas neoliberais não assegurou o fortalecimento e a organização da sociedade civil, bem como não garantiu a ampliação dos espaços públicos e da participação dos cidadãos na esfera pública.

As conquistas alcançadas não implicaram o abandono dos valores e dos costumes tradicionais, ancorados em um conceito clássico de conservadorismo. A própria sociedade não apresentou propostas de inovação institucional. Isso porque a sociedade é formada "por um conjunto de atores sociais, instituições e práticas tão diverso, heterogêneo e plural [...] com capitais culturais, simbólicos e organizacionais muito diferentes [...] que apenas em um sentido altamente simbólico representa algum tipo de unidade analítica" (OLVERA, 2002, p. 337).

$\mathrm{O}$ autor apresentou um elenco de propostas para melhorar a governabilidade democrática a partir da sociedade: a) do ponto de vista do sistema legal-institucional: a construção de um Estado de Direito; a instituição e o respeito à separação dos Poderes; a descentralização do poder; a profissionalização e a desclientelização dos aparatos estatais; a prestação de contas por parte dos governantes; a criação de instituições híbridas ou mistas de caráter não-estatal; $b$ ) do ponto de vista da rede associativa e dos movimentos sociais: a garantia da liberdade de associação; a criação de novas formas de reconhecimento jurídico das organizações civis; a garantia do acesso público aos meios de comunicação; c) do ponto de vista dos aspectos culturais: a universalização do acesso à educação; a realização de campanhas maciças de educação cívica; a distribuição da renda; a generalização da cultura da tolerância; d) do ponto de vista do caráter das organizações da sociedade civil: a transparência e organização democrática das instituições; o estabelecimento de um maior grau de institucionalidade e formalização das organizações; o respeito à pluralidade; a profissionalização das organizações; a recuperação da relação entre ONGs e os movimentos populares.

Em nosso ver, o livro cumpriu o propósito da pesquisa internacional, ao apresentar um panorama das diversas experiências realizadas no Brasil, que expressam, por meio da criação de espaços públicos, as múltiplas modalidades de relação entre a sociedade civil e o Estado. Contudo, deixou a desejar no que tange à realização de uma análise mais profunda e sistemática acerca do movimento que as mesmas percorreram ao longo de sua emergência na década de 1980, bem como das conexões entre si e de seus respectivos impactos.

Para concluir, tomaremos como referência as anotações sobre os demais países da América Latina assina- 
lando que o enfoque da construção da democracia e da instituição dos espaços públicos no Brasil adquire um patamar de superioridade, ao menos sob o aspecto formal, pois muitos dos aspectos relatados acima já estão asseverados. Requer, todavia, a persistência do apoio institucional, aliado à fixação de relações horizontais e solidárias e ao estabelecimento permanente da pactuação e do consenso, reconhecendo os conflitos na busca da unidade sem desrespeitar a pluralidade.

Todavia, é imprescindível salientarmos que a democracia participativa é um processo em construção, que apenas se inicia pelo estabelecimento de um marco legal e pela constituição de alguns espaços públicos. Necessariamente, ela deve vir acompanhada de experiências vivenciadas através das diversas arenas e dos instrumentos de participação política, marcados, sobretudo, pelo tipo e pelo grau de relação que, em cada momento histórico, é passível de ser firmado entre o Estado e a sociedade civil, na gestão da coisa pública.

Portanto, no processo de análise das experiências acima relatadas, cabe com propriedade o enfoque pedagógico de formação e exercício da cidadania, cunhado de avanços e retrocessos, mas sob a ótica da descentralização político-jurídico-administrativa, da participação popular e do controle social.

Em contraposição, não se mostra aconselhável realizar uma análise pendular da matéria, isto é, ou a sobrevalorização dos espaços públicos, independentemente dos percalços do presente, ou a comparação cética da definição entre o formal e o ideal, tendo as experiências como parâmetro, e a conclusão pela sua inviabilidade concreta. Os indícios observados deixam transparecer a possibilidade de construção e reconstrução permanente dos espaços públicos, direcionando-os para uma atuação com procedimentos democráticos.

Recebida em 15 de abril de 2002 . Aprovada em 14 de maio de 2002.

Denise Ratmann Arruda Colin (colin@terra.com.br) é mestranda em Sociologia na Universidade Federal do Paraná (UFPR) e Assistente Social do Ministério Público do Estado do Paraná.

\section{REFERÊNCIAS BIBLIOGRÁFICAS}

ALVAREZ, S. \& DAGNINO, E. 1995. Para além da democracia realmente existente : movimentos sociais, a nova cidadania e a configuração de espaços públicos alternativos. Trabalho apresentado no XIX Encontro Anual da Associação Nacional de Pós-graduação em Ciências Sociais, em outubro de 1995, Caxambu, Minas Gerais. Digit.

AVRITZER, L. 2002. O orçamento participativo : as experiências de Porto Alegre e Belo Horizonte In : DAGNINO, E. (org.). Sociedade civil e espaços públicos no Brasil. São Paulo : Paz e Terra.

BORBA, J. 2000. Técnica, política e poder na administração pública municipal : o caso do planejamento de Porto Alegre (1989-1996). Trabalho apresentado no $2^{\circ}$ Encontro da Associação Brasileira de Ciência Política, realizado de 20 a 24 de novembro de 2000, na Pontifícia Universidade Católica de São Paulo. Digit.

DAHL, R. 1997. Poliarquia. Participação e oposição. São Paulo : Edusp.

DIAS, M. R. 2000. Constrangimento, renúncia e reação : efeitos do orçamento participativo sobre a Câmara Municipal de Porto Alegre. Trabalho apresentado no $2^{\circ}$ Encontro da Associação Brasileira de Ciência Política, realizado de 20 a 24 de novembro de 2000, na Pontifícia Universidade Católica de São Paulo. Digit.

ESMERALDO, G. G. S. L. \& SAID, M. A. 2002. Conselho Cearense de Direitos da Mulher - espaço de interlocução entre as demandas dos movimentos de mulheres e o Estado. In : DAGNINO, E. (org.). Sociedade civil e espaços públicos no Brasil. São Paulo : Paz e Terra.

FIGUEIREDO, A. C. \& LIMONGI, F. 1994. O processo legislativo e a produção legal no Congresso pósConstituinte. Novos Estudos CEBRAP, São Paulo, n. 38, p. 24-37, mar.

MOUFFE, C. 2001. Globalização e cidadania democrática. Trabalho apresentado para o Programa de PósGraduação em Direito da Pontifícia Universidade Católica do Paraná, em 19 de abril de 2001. Digit. 
OLVERA, A. J. 2002. Sociedade civil e governabilidade no México. In : DAGNINO, E. (org.). Sociedade civile espaços públicos no Brasil. São Paulo : Paz e Terra.

PANFICHI, A. \& CHIRINOS, P. V. M. 2002. Sociedade civil e governabilidade democrática nos Andes e no Cone Sul : uma visão panorâmica na entrada do século XXI. In : DAGNINO, E. (org.). Sociedade civil e espaços públicos no Brasil. São Paulo : Paz e Terra.

PUTNAM, R. 1996. Comunidade e democracia : a experiência da Itália moderna. Rio de Janeiro : Fundação Getúlio Vargas.

SOUZA, M. A. 2002. As relações entre o Movimento dos Sem-Terra e o Estado : programas de alfabetização de jovens e adultos no Paraná. In : DAGNINO, E. (org.). Sociedade civil e espaços públicos no Brasil. São Paulo : Paz e Terra.

TATAGIBA, L. 2002. Os Conselhos Gestores e a democratização das políticas públicas no Brasil. In :DAGNINO, E. (org.). Sociedade civil e espaços públicos no Brasil. São Paulo : Paz e Terra.

TEIXEIRA, A. C. C. 2002. A atuação das organizações não-governamentais : entre o Estado e o conjunto da sociedade. In : DAGNINO, E. (org.). Sociedade civil e espaços públicos no Brasil. São Paulo : Paz e Terra.

TEIXEIRA, E. C. 2000. Conselhos de políticas públicas : efetivamente uma nova institucionalidade participativa? In : CARVALHO, M. C. \& TEIXEIRA, A. C. C. (orgs.). Conselhos gestores de políticas públicas. São Paulo: Polis. 